\title{
Urinary Excretion Rates of 6-Keto-PGF $1 \alpha$ in Preterm Infants Recovering from Respiratory Distress with and without Patent Ductus Arteriosus
}

\author{
H. W. SEYBERTH, ${ }^{(32)}$ H. MÜLLER, H. E. ULMER, AND L. WILLE \\ Department of Pediatrics, University of Heidelberg, Heidelberg, Federal Republic of Germany
}

\begin{abstract}
Summary
Patency of the ductus arteriosus in preterm infants is mediated by vasodilating prostanoids; however, reliable methods to monitor prostanoid activity or production in preterm infants are lacking. We measured the excretion rates of major and characteristic urinary metabolites of prostacyclin $\left(\mathrm{PGI}_{2}\right), \mathrm{PGE}_{1}$, and $\mathrm{PGE}_{2}, 6$ keto-PGF ${ }_{1 \alpha}$, and $7 \alpha$-hydroxy-5,11-diketotetranorprostane-1,16dioic acid (PGE-M), respectively. Besides these parameters which reflect total body prostanoid turnover and production, the urinary levels of $\mathrm{PGE}_{2}$ and $\mathrm{PGF}_{2 \alpha}$, the primary prostaglandins, were measured as an index of renal prostanoid synthesis. There were four study groups. One contained 11 thriving preterm infants; a second, six preterm infants with respiratory distress syndrome (RDS); a third, 30 preterm infants with RDS and patent ductus arteriosus (PDA); and a fourth, nine fullterm infants. All infants with RDS required artificial ventilation. There were no significant differences in PGE-M, PGE $_{2}$, and $\mathbf{P G F}_{2 \alpha}$ excretion rates among the various groups; however, a significant increase of the 6-keto-PGF $F_{1 \alpha}$ excretion rates was observed in the groups of infants with RDS and with and without PDA $(P<0.01$ and $P<0.02$, respectively). Spontaneous $(n=2)$ or indomethacin-induced $(n=6)$ closure of PDA was associated with weaning from the respirator and a concomitant drop into the normal and subnormal range of the excretion rates of 6-keto-PGF ${ }_{1 \alpha}(P<$ $0.01)$ and PGE-M $(P<0.02)$.
\end{abstract}

\section{Abbreviations}

GC-MS, gas chromatography-mass spectrometry

PDA, patent ductus arteriosus

$P G$, prostaglandin

PGE-M, $7 \alpha$-hydroxy-5,11-diketotetranorprostane-1,16-dioic acid

PGI $_{2}$, prostacyclin

RDS, respiratory distress syndrome

There is increasing evidence that persistent PDA in preterm infants with RDS is mediated by vasodilating prostanoids $(4,18)$. But it is still a matter of debate whether increased prostanoid production or increased prostanoid sensitivity of ductal tissue is the major cause of PDA persistence in preterm infants with RDS $(2,3)$. It is not known whether $\mathrm{PGI}_{2}$ or $\mathrm{PGE}_{2}$, both vasodilating prostanoids, is the actual mediator of ductal dilation in these infants. Nor is it known which organ or tissue is mainly involved in the production of these prostanoids.

Several attempts to assess prostanoid activity by radioimmunologic determinations of $\mathrm{PGE}_{2}$ in the peripheral circulation of preterm infants have not led to conclusive results $(2,8,15)$. This is not unexpected due to the numerous drawbacks related to measurements of primary (parent) PGs (11). There are four major concerns of this approach. 1) Very low circulating levels of primary PGs are expected because of the very rapid metabolism of these compounds and single blood measurements might easily miss rapid fluctuation of PG release. 2) Primary PGs might be released from platelets and white cells during collection and handling of blood samples. 3) Protein binding of prostanoid in blood and plasma may interfere with several conventional extraction procedures. 4) Radioimmunologic assays of prostanoids may lack the specificity necessary for measurements in complex biologic matrices, such as plasma $(1,11,12,16)$.

To overcome most of these problems, another approach for the assessment of endogenous prostanoid production has been recommended. This is the determination of the excretion rates of major and characteristic prostanoid metabolites in urine, which are thought to be a reflection of total body prostanoid turnover and production (11). Furthermore, this approach is noninvasive which removes ethical problems in human studies and allows serial assessments even in small individuals.

Based on these considerations, we planned the present study to evaluate prostanoid production in preterm infants with RDS and PDA by determining the excretion rates of characteristic urinary metabolites of the two major prostanoid vasodilators, $\mathrm{PGI}_{2}$ and $\mathrm{PGE}_{2}$. The urinary metabolite selected for $\mathrm{PGI}_{2}$ was $6-$ keto-PGF ${ }_{1 \alpha}$ and that for PGE 2 was PGE-M. Urinary PGE-M levels have already been successfully used to assess increased PGE production under various clinical conditions including studies in infancy $(9,25,26,27)$. Urinary 6 -keto-PGF ( $_{\alpha \alpha}$ levels also appear to be a reflection of systemic $\mathrm{PGI}_{2}$ production as a marked increase of urinary 6-keto- $\mathrm{PGF}_{1 \alpha}$ excretion has been shown during $\mathrm{PGI}_{2}$ infusion in primates and humans $(21,29)$. Furthermore, direct and indirect evidence does not identify the kidney as the major organ of urinary 6-keto-PGF ${ }_{1 \alpha}(22,24)$. For comparison between systemic and renal prostanoid production we measured the urinary levels of $\mathrm{PGE}_{2}$ and $\mathrm{PGF}_{2 \alpha}$, the primary PGs, that are thought to reflect primarily renal PG synthesis $(10)$. All four prostanoids were analyzed by quantitative GC-MS which provides the most specific technique available for trace analysis of prostanoids in complex biologic samples (11), particularly when using capillary gas chromatography-columns (7).

\section{MATERIALS AND METHODS}

Study population. For comparison between pre- and fullterm infants with various disease states the following four groups were selected. 1) Eleven thriving preterm infants without any evidence 
of RDS and without PDA were selected at random from the newborn care unit. 2) Six preterm infants with RDS who required artificial ventilation but who did not have clinical signs of PDA at any time during their hospitalization. 3) Thirty artificially ventilated preterm infants with RDS and typical clinical signs of PDA. 4) Nine fullterm infants recovering from minor postnatal adaption problems or with initially suspected infections that were finally disproved by culture or other laboratory tests. Two infants of these groups were small for gestational age. Clinical data on the four groups are shown in Table 1.

The diagnosis of RDS was based on grunting and retractions shortly after birth, the requirement for increased ambient oxygen concentrations, radiologic findings of bilateral reticulogranular pattern, air bronchogram, and diminished lung volume. Arterial $\mathrm{PaO}_{2}$ was maintained between 55 and 65 torr in all of them through a combination of increased oxygen concentration, a peak inspiratory pressure of $25 \mathrm{~cm} \mathrm{H}_{2} \mathrm{O}$ at a respiratory rate of $25-30 / \mathrm{min}$, a positive endexpiratory pressure of $4-6 \mathrm{~cm} \mathrm{H}_{2} \mathrm{O}$, and an inspiration time of $1.5 \mathrm{sec}$ (Neonatal Intensive Care Respirator MVP-10, Bio-Med Divices. Inc., Stamfort, CT or Intensive respirator BP 200, Bournes Medical Systems, Inc., Riverside, CA). The clinical diagnosis of PDA with a left-to-right shunt was based on the presence of an infraclavicular and precordial systolic murmur, hyperdynamic precordium, bounding pulses and radiologic features of pulmonary plethora. The daily fluid intake ranged between $100-150 \mathrm{ml} / \mathrm{kg}$ in infants with a birth weight less than $1000 \mathrm{~g}, 80-100 \mathrm{ml} / \mathrm{kg}$ in those infants with a birth weight of $1000-1500 \mathrm{~g}$ and $80 \mathrm{ml} / \mathrm{kg}$ in infants with a birth weight of more than $1500 \mathrm{~g}$.

At least $2 \mathrm{~d}$ before and during urine collection the infants were not on drugs influencing renal blood flow or function such as diuretics and methylxanthines. Before delivery the mothers did not receive any drugs known to inhibit prostaglandin synthesis.

Urine was collected for $12 \mathrm{~h}$. Suprapubic compression was performed at the beginning and the end of each collection to make sure that the bladder was empty. Urine was fractionally collected in U-bags (Hollister Inc., Ballina, Ireland). The urine specimens were refrigerated, pooled, and stored at $-80^{\circ} \mathrm{C}$ until analysis. In all infants urinary flow was recorded and in all preterm infants in whom serum creatininely concentrations were monitored routinely, the creatinine clearances were calculated to ascertain comparable kidney function between the groups.
Six preterm infants with PDA and RDS between the second and eleventh day of life (median, $4.5 \mathrm{~d}$ ) were restudied 1 wk later during indomethacin treatment which lead to closure of the PDA. Two additional infants showed spontaneous closure of PDA in a $1 \mathrm{wk}$ follow-up. By that time all eight infants were successfully weaned from the respirator. In comparison, five agematched thriving preterm infants without RDS and PDA were studied in a similar way at the fourth and the eleventh postnatal day.

The study has been approved by the local Ethical Committee and written informed consent was obtained from the parents before the infants entered the study.

Analytical methods. The procedure of urinary sample preparation (including preparative high performance liquid chromatography) and the final determination of prostanoid levels by combined capillary column GC-MS, (using deuterated PG analogues as internal standards) were carried out as previously described $(7,17,23)$. Urinary excretion rates of prostanoids were expressed as nanograms per hour per 1.73 square meters body surface area. In previous studies on infants and children of various ages, this expression of urinary prostanoid excretion gave the least scatter, particularly for the prostaglandin metabolites in the very young infants (23).

Statistical methods. Statistical differences between the groups were evaluated with the rank-sign sum test. Significant intraindividual changes in urinary excretion rates of prostanoids were assessed by the Wilcoxon test for pair differences.

\section{RESULTS}

As shown in Figure 1, urinary excretion rates of both 6-keto$\mathrm{PGF}_{1 \alpha}$ and PGE-M, prostanoid metabolites, were not significantly different in the pre- and fullterm infants. But preterm infants with RDS, excreted increased amounts of 6-keto-PGF $F_{1 \alpha}$ in two-thirds of our population irrespective of the presence of symptomatic PDA $(P<0.02$ and $P<0.01$, respectively). No such elevated excretion rates of PGE-M were observed in these two groups except that there was a somewhat more marked scatter in both directions of the normal range in the preterm infants with RDS and PDA. When urinary excretion rates of 6 keto-PGF ${ }_{1 \alpha}$ and PGE-M were measured, an increased production of one or both vasodilating prostanoids was observed in almost

Table 1. Clinical data for the study groups

\begin{tabular}{|c|c|c|c|c|}
\hline \multirow{4}{*}{$\begin{array}{c}\text { RDS } \\
\text { PDA } \\
(n)\end{array}$} & \multicolumn{3}{|c|}{ Preterm infants } & \multirow{4}{*}{$\begin{array}{c}\text { Fullterm infants } \\
\begin{array}{c}- \\
- \\
(9)\end{array}\end{array}$} \\
\hline & $-*$ & $+\dagger$ & + & \\
\hline & - & - & + & \\
\hline & (11) & $(6)$ & $(30)$ & \\
\hline $\operatorname{Sex}, M / F$ & $7 / 4$ & $4 / 2$ & $22 / 8$ & $8 / 1$ \\
\hline \multicolumn{5}{|c|}{ Gestational age (wk) } \\
\hline Median & 34 & 32 & 31 & 38 \\
\hline Range & $29-36$ & $28-34$ & $28-36$ & $38-40$ \\
\hline Range & $700-2250$ & $700-2300$ & $740-2300$ & $1930-3460$ \\
\hline \multicolumn{5}{|l|}{ Postnatal age (d) } \\
\hline Median & 4 & 4 & 4 & 6 \\
\hline Range & $3-13$ & $2-12$ & $2-24$ & $2-26$ \\
\hline \multicolumn{5}{|c|}{ Diuresis $\left[\mathrm{ml} /\left(\min \cdot 1.73 \mathrm{~m}^{2}\right)\right]$} \\
\hline Median & 1.0 & 0.8 & 1.1 & 0.7 \\
\hline Range & $10.0-20.3$ & $6.7-27.2$ & $3.1-43.5$ & $\ldots$ \\
\hline
\end{tabular}

* -, Without respiratory distress syndrome (RDS) or patent ductus arteriosus (PDA).

$\dagger+$, with RDS or PDA. 
$80 \%$ (23 out of 30 ) of the infants with PDA. The renal PG synthesis appeared not to be concomitantly stimulated with the systemic prostanoid production in preterm infants with PDA and RDS (Table 2). The low urinary levels of $\mathrm{PGE}_{2}$ in infants suffering only from RDS were not conclusive because of the small number of patients in this group.

The excretion of 6-keto-PGF ${ }_{1 \alpha}$ and PGE-M was reduced to the subnormal range in all six infants within $7 \mathrm{~d}$ of initiation of treatment with indomethacin (Fig. 2). In association with ductal constriction and weaning from the respirator, the urinary output of 6-keto-PGF ${ }_{1 \alpha}$ decreased in each infant. The excretion rates of the two patients with spontaneous ductal closure followed the same lines as those infants with indomethacin treatment. This decline in prostanoid excretion rates appeared not to be affected by changes in kidney function because diuresis and creatinine clearances did not significantly differ before and after ductal closure.

\section{DISCUSSION}

This study provides evidence that increased systemic prostanoid production may be involved in the pathogenesis of persistent PDA in preterm infants with RDS. In the groups of preterm infants with RDS alone and with RDS plus PDA, urinary excretion of 6-keto $\mathrm{PGF}_{1 \alpha}$ was significantly elevated in most infants. No significant urinary excretion rates of PGE-M and the renally derived $\mathrm{PGF}_{2}$ and $\mathrm{PGF}_{2 \alpha}$ were observed in these infants.

The fact that there were no differences in the excretion of 6keto-PGF $1 \alpha$ between infants with RDS and with and without PDA supports the concept that increased ductal prostanoid sensitivity is also involved in the pathogenesis of persistent PDA. Also in accordance with this hypothesis, there is the finding that despite the existence of PDA, seven infants excreted normal levels of both prostanoid metabolites in the urine. The drawbacks, however, in the assessment of endogenous prostanoid
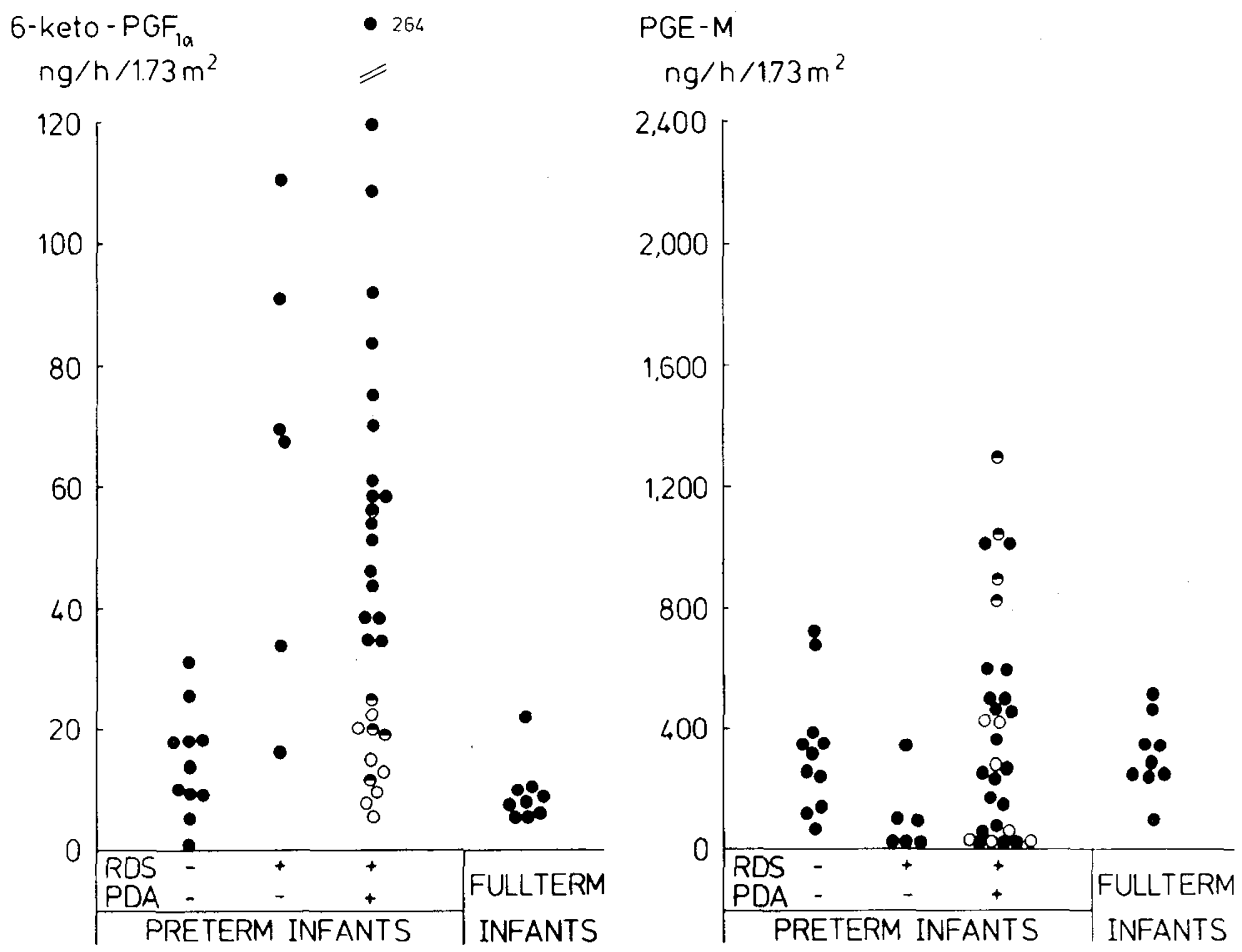

Fig. 1. Comparison of urinary excretion rates of 6-keto-PGF ${ }_{1 \alpha}$ and PGE-M in thriving preterm infants without RDS and without PDA ( $\left.n=11\right)$, in preterm infants with RDS and without PDA $(n=6)$, in preterm infants with RDS and PDA $(n=30)$ and in fullterm infants without PDA and RDS $(n=9)$. All preterm infants with RDS required artificial ventilation. The open symbols represent the data of seven infants with PDA whose excretion rates of both 6-keto-PGF $1 \alpha$ and PGE-M were in the control range. The half closed symbols represent the data of four infants with RDS whose excretion rates of PGE-M were evaluated but not that of 6-keto-PGF $F_{1 \alpha}$. Presence or absence of RDS and PDA are indicated as plus and minus, respectively. Abbreviations, see "Abbreviations."

Table 2. Urinary excretion rates of $P G E_{2}$ and $P G F_{2 \alpha}$ in pre- and fullterm infants

\begin{tabular}{|c|c|c|c|c|}
\hline \multirow[b]{2}{*}{$\begin{array}{c}\text { RDS } \\
\text { PDA } \\
(n)\end{array}$} & \multicolumn{3}{|c|}{ Preterm infants } & \multirow{2}{*}{$\begin{array}{c}\text { Fullterm infants } \\
\begin{array}{c}- \\
- \\
(9)\end{array}\end{array}$} \\
\hline & $\begin{array}{c}-^{*} \\
- \\
(11)\end{array}$ & $\begin{array}{c}+\dagger \\
- \\
(5) \neq\end{array}$ & $\begin{array}{c}+ \\
+ \\
(28)+\end{array}$ & \\
\hline \multicolumn{5}{|l|}{$\mathrm{PGE}_{2}\left[\mathrm{ng} /\left(\mathrm{h} \cdot 1.73 \mathrm{~m}^{2}\right)\right]$} \\
\hline Median & 6.0 & n.d $\S$ & 5.9 & 8.8 \\
\hline Range & $0.9-11.4$ & n.d. -9.8 & n.d. -37.9 & $3.0-40.1$ \\
\hline \multicolumn{5}{|l|}{$\mathrm{PGF}_{2 \alpha}\left[\mathrm{ng} /\left(\mathrm{h} \cdot 1.73 \mathrm{~m}^{3}\right)\right]$} \\
\hline
\end{tabular}

* -, Without respiratory distress syndrome (RDS) or patent ductus arteriosus (PDA).

$\dagger+$, With RDS or PDA.

$\$$ In only three infants, prostanoid metabolites, but not $\mathrm{PGE}_{2}$ and $\mathrm{PGF}_{2 \alpha}$, could be determined in the urine sample collected during a 12-h period. $\S$ Not detectable [detection limit was about $0.3 \mathrm{ng} /\left(\mathrm{h} \cdot 1.73 \mathrm{~m}^{3}\right)$ ]. 


$$
6 \text {-keto-PGF } 1 \alpha
$$

PGE-M
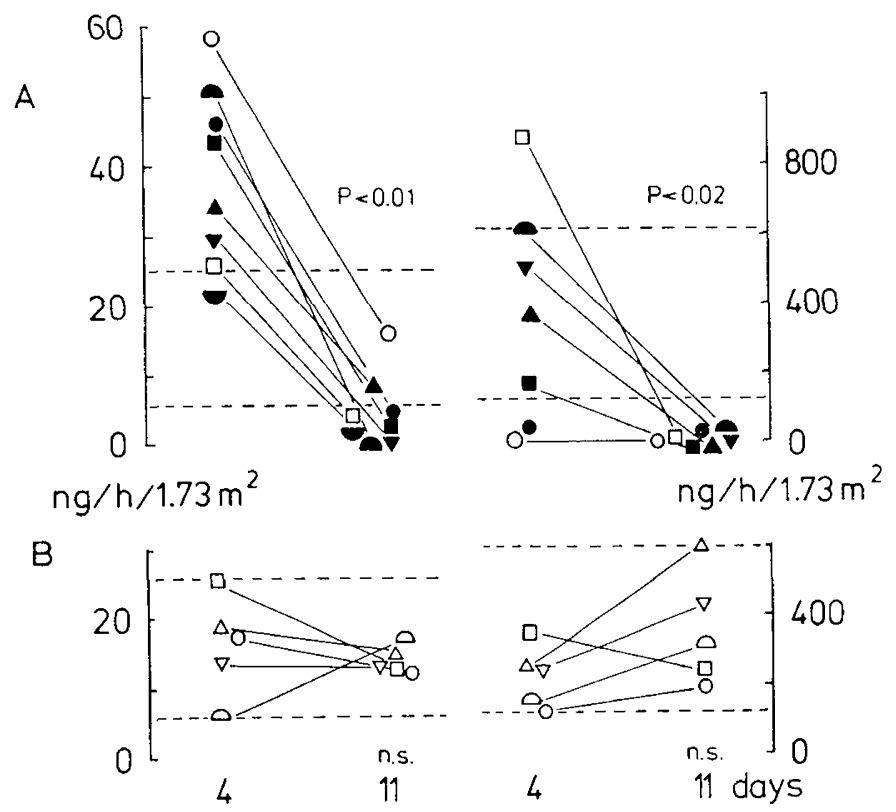

P.N. - AGE

Fig. 2. (A) Spontaneous (open symbols) or indomethacin induced (closed symbols) decline of urinary excretion rates of 6-keto-PGF ${ }_{1 \alpha}$ and PGE-M in eight infants with PDA and RDS which was associated with closure of PDA and weaning from the respirator. At the time of restudying the indomethacin-treated infants, the indomethacin serum levels were $400-775 \mathrm{mg} / \mathrm{ml} 12 \mathrm{~h}$ after dosing. $(B)$ For comparison, postnatal changes of urinary excretion rates of 6-keto-PGF ${ }_{1 \alpha}$ and PGE-M in five age-matched thriving preterm infants without PDA and RDS. The area between the broken lines represents the range of prostanoid metabolites excretion of the five control infants during the postnatal (p.n.) period of the fourth and eleventh day of life.

production by the urinary excretion rates of their metabolite also need some consideration. Ideally, prostanoid metabolites should be stable and renal function should not be affected. This might not always be the case in critical situations such as in respiratory distress and circulatory failure; therefore, one can not exclude false negative results due to insufficient metabolic transformation and/or decreased renal elimination of prostanoid metabolites. Fortunately, $\mathrm{PGI}_{2}$ decomposes spontaneously by hydrolysis to the inactive 6-keto- $\mathrm{PGF}_{1 \alpha}$ at a physiologic $\mathrm{pH}$ in aqueous solution and does not require any enzymatic activity. We cannot dismiss the likelihood that $\mathrm{PGI}_{2}$ may be, in part, enzymatically metabolized before hydrolysis in the body and that renal function may to some extent influence urinary 6-keto-PGF ${ }_{1 \alpha}$ levels. In contrast to the urinary levels of 6-keto- $\mathrm{PGF}_{1 \alpha}$, the renal excretion of PGE-M is exclusively dependent on intact PGE metabolism which includes 15-hydrogenation, delta-13-reduction and beta and omega oxidation (13). This different metabolic fate could explain why the urinary excretion rate of 6-keto-PGF ${ }_{1 \alpha}$ appeared to be a better reflection of increased systemic prostanoid production in critically ill infants, although urinary 6-keto-PGF $F_{1 \alpha}$ levels were only one-tenth or less than PGE-M.

With respect to the increased 6-keto- $\mathrm{PGF}_{1 \alpha}$ excretion in preterm infants with RDS requiring artificial ventilation, irrespective of the existence of PDA, one may speculate that the mechanically ventilated lung is one of the organs that contribute to the increased systemic $\mathrm{PGI}_{2}$ production. In comparison to other prostanoids, the lung appears to synthesize $\mathrm{PGI}_{2}$ most abundantly (28) besides the vascular tissue $(4,20,30)$. In experimental (28) as well as in clinical studies (6) several investigators have shown that artificial ventilation of the normal lung will provide a stimulus for the pulmonary release of $\mathrm{PGI}_{2}$. This has also been shown in lungs of fetal animals $(14,19)$ and during the application of positive endexpiratory pressure in dogs (5). The concomitant drop of the elevated 6-keto-PGF ${ }_{1 \alpha}$ excretion and the weaning from the respirator, which was associated with the spontaneous closure of PDA (Fig. 2), are compatible with this hypothesis. Furthermore, we have reported (25) that after successful ductal closure with short-term indomethacin therapy, PDA relapses were frequently seen in those infants with prolonged artificial ventilation that was primarily required for pulmonary lesions such as lung infections and atelectasis or apneic spells.

We therefore propose the following sequence of events: 1) development of RDS or other pulmonary lesions which require artificial ventilation; 2) this mechanical intervention causes periodic distension and permanent shear stress on the pulmonary tissue; 3) this stress causes release of arachidonic acid, the major substrate for prostanoid synthesis, from phospholipids in cell membranes; 4) subsequently $\mathrm{PGI}_{2}$ and/or its metabolites, including the more stable but still very vasoactive 6-keto- $\mathrm{PGE}_{1 \alpha}(4)$, are released and reach the pulmonary circulation and the ductus arteriosus. Vasodilatation of the ductus and the pulmonary vessels will lead to a further increase of shunting across the PDA and a vicious circle is established.

The parallelism between ductal constriction, weaning from the respirator and the decline in urinary 6-keto-PGF ${ }_{1 \alpha}$ level, as shown in this study, does not demonstrate by itself a close causal relationship between persistent PDA and increased $\mathrm{PGI}_{2}$ production. But these findings are, at least, compatible with this assumption. Further studies will show if monitoring urinary excretion of 6-keto-PGF ${ }_{1 \alpha}$ in preterm infants with RDS is helpful in identifying the factors that stimulate systemic $\mathrm{PGI}_{2}$ production and if, by eliminating them, the incidence of PDA decreases.

\section{REFERENCES AND NOTES}

1. Blair, I. A., Barrow, S. E., Waddell, K. A., Lewis, P. J., and Dollery, C. T.: Prostacyclin is not a circulating hormone in man. Prostaglandins, 23: 579 (1980).

2. Clyman, R. I., Brett, C., and Mauray, F.: Circulating prostaglandin $E_{2}$ concentrations and incidence of patent ductus arteriosus in preterm infants with respiratory distress syndrome. Pediatrics, 66: 725 (1980).

3. Clyman, R. I., Mauray, F., Roman, C., Rudolph, A. M., and Heymann, M. A.: Circulating prostaglandin $E_{2}$ concentrations and patent ductus arteriosus in fetal and neonatal lambs. J. Pediatr., 97: 455 (1980).

4. Coceani, F. and Olley, P. M.: Role of prostaglandins, prostacyclin, and thromboxanes in the control of prenatal patency and postnatal closure of the ductus arteriosus. Semin. Perinatol., 4: 109 (1980).

5. Dunham, B. M., Grindlinger, G. A., Utsunomiya, T., Krausz, M. M., Hechtmann, H. B., and Shepro, D.: Role of prostaglandins in positive endexpiratory pressure-induced negative inotropism. Am. J. Physiol., 241: $\mathrm{H783}$ (1981).

6. Edlund, A., Bomfim, W., Kaijser, L., Olin, C., Patrono, C., Pinca, E., and Wennmalm, $\AA$.: Pulmonary formation of prostacyclin in man. Prostaglandins, 22: 323 (1981).

7. Erlenmaier, T., Müller, H., and Seyberth, H. W.: Combined capillary column gas chromatography-mass spectrometric method for the quantitative analysis of urinary prostaglandins. J. Chromatogr., 163: 289 (1979).

8. Friedman, Z. and Demers, L. M.: Essential fatty acids, prostaglandins, and respiratory distress syndrome of the newborn. Pediatrics, 61: 341 (1978).

9. Friedman, Z., Seyberth, H. W., Lamberth, E. L., and Oates, J. A.: Decreased prostaglandin $\mathrm{E}$ turnover in infants with essential fatty acid deficiency. Pediatr. Res., I2: 711 (1978).

10. Frölich, J. C., Wilson, T. W., Sweetman, B. J., Smigel, M., Nies, A. S., Watson, J. T., and Oates, J. A.: Urinary prostaglandins: identification and origin. J. Clin. Invest., 55: 763 (1975).

11. Granström, E. and Samuelsson, B.: Quantitative measurement of prostaglandins and thromboxanes: general considerations. In: Frölich, J. C. Ed.: Advances in Prostaglandin Thromboxane Research. p. 1 (Raven Press, New York, 1978).

12. Greaves, $M$. and Preston, F. E.: Plasma 6-keto-prostaglandin $F_{1 \alpha}$ : fact or fiction. Thromb. Res., 26: 145 (1982).

13. Hamberg, M. and Samuelsson, B.: On the metabolism of prostaglandins $E_{1}$ and $E_{2}$ in the guinea pig. J. Biol. Chem., 247: 3495 (1972).

14. Leffler, C. W. and Hessler, J. R.: Perinatal pulmonary prostaglandin production. Am. J. Physiol., 241: H756 (1981)

15. Lucas, A. and Mitchell, M. D.: Plasma-prostaglandins in preterm infants neonates before and after treatment for patent ductus arteriosus. Lancet, 2 : 130 (1978).

16. Morris, H. G., Sherman, N. A., and Shepperdson, F. T.: Variables associated with radioimmunoassay of prostaglandins in plasma. Prostaglandins, 21:771 (1981). 
17. Müller, H., Mrongovius, R., and Seyberth, H. W.: Improved sample preparation for the quantitative mass spectrometric determination of prostaglandins in biological samples. J. Chromatogr., 226: 450 (1981).

18. Olley, P. M. and Coceani, F.: Prostaglandins and the ductus arteriosus. Annu. Rev. Med., 32: 375 (1981).

19. Omini, C., Brunelli, G., Folco, G. C., Marini, A., Pasargiklian, R., and Berti, F.: Prostacyclin $\left(\mathrm{PGI}_{2}\right)$ generation in lungs of fetal and newborn rabbit. Prostaglandins, 21: 345 (1981).

20. Pace-Asciak, C. R. and Rangaraj, G.: The 6-keto-prostaglandin $F_{1 \alpha}$ pathway in the lamb ductus arteriosus. Biochim. Biophys. Acta, 486: 583 (1977).

21. Rosenkranz, B., Fischer, C., Weimer, K. E., and Frölich, J. C.: Metabolism of prostacyclin and 6-keto-prostaglandin $\mathrm{F}_{1 \alpha}$ in man. J. Biol. Chem., 255: 10194 (1980).

22. Rosenkranz, B., Kitajima, W., and Frölich, J. C.: Relevance of urinary 6-ketoprostaglandin $\mathrm{F}_{1 \alpha}$ determination. Kidney Int., 19: 755 (1981).

23. Seyberth, H. W., Müller, H., Erlenmaier, T., and Mrongovius, R.: Mass spectrometric determination of urinary prostaglandins in preterm infants. Eur. J. Clin. Pharmacol., I8: 89 (1980).

24. Seyberth, H. W., Müller, H., Soeding, K., Wille, L, and Hackenthal, E. Urinary excretion rate of 6-keto-PGF ${ }_{1 \alpha}$ as an index of circulating $\mathrm{PGI}_{2}$. In: B. Samuelsson, P. W. Ramwell, and R. Paoletti. Advances in Prostaglandin Thromboxane Leukotriene Research. p 533 (Raven Press, New York, 1983).

25. Seyberth, H. W., Müller, H., Wille, L., Plückthun, H., Wolf, D., and Ulmer, H. E.: Recovery of prostaglandin production associated with reopening of the ductus arteriosus after indomethacin treatment in preterm infants with respiratory distress syndrome. Pediatr. Pharmacol., 2: 127 (1982)

26. Seyberth, H. W., Segre, G. V., Morgan, J. L., Sweetman, B. J., Potts, J. T., and
Oates, J. A.: Prostaglandins as mediators of hypercalcemia associated with certain types of cancer. N. Engl. J. Med., 293: 1278 (1975).

27. Seyberth, H. W Sweetman, B. J., Frölich, J C and Oates, J A. Quantification of the major urinary metabolite of the E prostaglandins by mass spectrometry: evaluation of the method's application to clinical studies. Prostaglandins, 11: 381 (1976)

28. Splawinski, J. and Gryglewski, R. J.: Release of prostacyclin by the lung. Bull. Eur. Physiopathol. Respir., 17: 553 (1981).

29. Sun, F. F. and Taylor, B. M.: Metabolism of prostacyclin in cynomolgus monkey. Prostaglandins, 21: 307 (1981).

30. Terragno, N. A. and Terragno, A.: Prostaglandin metabolism in the fetal and maternal vasculature. Fed. Proc., 38: 75 (1979)

31. We are indepted to Mrs Karin Soeding for the high standard of technical assistance and to the nurses of the intensive care unit and the nursery of the Department of Pediatrics of the University of Heidelberg for their excellent collaboration in the wards. Unlabeled and deuterated prostanoids were generously provided by Drs. U. Axen and J. Pike, The Upjohn Company (Kalamazoo, MI, USA).

32. Requests for reprints should be addressed to: Prof. Dr. H. W. Seyberth, Universitäts-Kinderklinik, Im Neuenheimer Feld 150, D-6900 Heidelberg 1, Federal Republic of Germany.

33. This study was supported by a grant from the Deutsche Forschungsgemein schaft (Se 263). Dr. Seyberth is a Heisenberg scholar of the Deutsche Forschungsgemeinschaft.

34. Received for publication September 6, 1982.

35. Accepted for publication September 12, 1983.

\title{
Body Water Measurements in Premature and Older Infants Using $\mathrm{H}_{2}{ }^{18} \mathrm{O}$ Isotopic Determinations
}

\author{
FREDERICK L. TROWBRIDGE ${ }^{(7)}$ GEORGE G. GRAHAM, WILLIAM W. WONG, \\ E. DAVID MELLITS, JUDITH D. RABOLD, LUCINDA S. LEE, MERCEDES P. CABRERA, AND \\ PETER D. KLEIN \\ School of Hygiene and Public Health, and the School of Medicine, Johns Hopkins University, \\ Baltimore, Maryland and USDA/ARS Children's Nutrition Research Center, Department of Pediatrics, Baylor \\ College of Medicine and Texas Children's Hospital, Houston, Texas, USA
}

\section{Summary}

Total body water was measured by $\mathrm{H}_{2}{ }^{18} \mathrm{O}$ stable isotope dilution in two groups: in premature infants without complications, who were studied from $8 \mathrm{~d}$ of age until discharge; and in Peruvian subjects aged 6-36 mo, who were in the long-term convalescent stage of recovery from malnutrition. Results indicated that reliable total body water estimates can be obtained from sample volumes as small as $50 \mu \mathrm{l}$ of urine or plasma using a gas-isotoperatio mass spectrometer equipped with an automated purification inlet system. Results from 21 studies in 10 Peruvian infants indicated substantially completed isotope equilibration in plasma by $2 \mathrm{~h}$ after the dose; total body water estimates from the 2 -h samples averaged $98.7 \%( \pm 4.1)$ of 6 -h values. Samples obtained at 4-h postdose gave total body water estimates that averaged $99.0 \%( \pm 2.9)$ of the 6 -h value, showing essentially complete equilibration and reduced variability. Total body water estimates from urine samples collected $3-5$ h postdose were closely correlated with 6-h, plasma-based total body water values in both premature and older infants; however, some reduction in variability was observed when urine collection was extended to 5-7 h, at which time urine-based estimates averaged $98.8 \%( \pm 2.0)$ and $100.7 \%( \pm 3.1)$ of plasma-based values for prematures and older
Peruvian infants, respectively. The correlation between 5-7 h urine-based estimates of total body water with plasma-based values was $r=0.96$ for 30 studies in prematures and $r=0.99$ for 57 studies in older Peruvian infants. Data points adhered closely to the lines of identity in both study groups. These results suggest that noninvasive urine sampling techniques can be substituted for plasma sampling in body water studies in infants.

\section{Abbreviation}

TBW, total body water

TBW measurements in infants are useful for assessing body composition; however, infant studies require small samples, minimal invasiveness of procedures, and avoiding exposure to radioactive isotopes. The stable, naturally occurring oxygen- 18 isotope $\left({ }^{18} \mathrm{O}\right)$, when present in enriched concentrations as $\mathrm{H}_{2}{ }^{18} \mathrm{O}$, meets the requirements of infant body water studies because it lacks toxicity and its isotopic ratio is relatively easily measured by automated mass spectrometric techniques (3). $\mathrm{H}_{2}{ }^{18} \mathrm{O}$ was used for body water studies in adults (3) and adolescents (5); however, sample volumes of $1.0-1.5 \mathrm{ml}$ of urine, plasma, or saliva were 